\title{
Abstracts
}

Thomas Zerback, Carsten Reinemann and Angela Nienierza

Climate of opinion perception during the German federal election 2013: Perceived party popularity and expectations regarding their electoral success

We analyze the formation of judgments about the perceived popularity of political parties (perceived current opinion climate) and expectations about their future electoral performance (perceived future opinion climate). Based on representative survey data collected in Berlin during the run-up to the German federal elections 2013 we can show that perceived media slant and opinions in the personal social environment serve as the most important predictors of perceived party popularity. Interestingly, individual recall of current poll results hardly influences popularity evaluations. However, when forming expectations regarding the parties' future success poll results are the single most important source. For some parties, we also found respondents to project their political preferences on party popularity and expectations.

\section{Markus Tausendpfund}

Public support for European integration: an empirical analysis of local politicians

Within the discussion on stability and further development of the European Union the attitude of local politicians has not being paid a lot of attention so far. This is surprise for two reasons. On the one hand the EU has a great impact on the local area. On the other hand local politicians should help to explain decisions of the EU. More than 700 local politicians from 28 municipalities have been interviewed for the empirical analyses. The following conclusions can be drawn from the analysis: First, local politicians support the European Union. Second, the support varies between the municipalities. Third, support for the EU depends on both the contextual and the individual level although effects of the latter are more prevalent. 


\section{Thomas Krumm}

How effective are electoral thresholds? The effect of thresholds on the number of parties in the German Bundestag and in international comparison

In weighing the pros and cons of electoral thresholds, the Federal Constitutional Court in Germany has banned them at local and at European elections level in recent years. Against this background, the article asks for the possible impact of different thresholds on the total number of parties in the Bundestag.

According to the results of a simulation of lower thresholds and different voting behaviour in the period 1957 to 2013, the smallest increase in the number of parties is to be expected when lowering the hurdle from four to three per cent, the highest in the step from two to one per cent.

Furthermore, a quantitative international comparison suggests that in particular the age of a party system has a significant influence on fragmentation, while an effect of electoral thresholds could not be observed. Finally, the preference of many parties for the threshold option is interpreted in terms of the cartel party hypothesis. 